\title{
Unprecedented Far East Salmon Catches in 2018: What Should We Expect in Future?
}

\author{
Andrey S. Krovnin, Nataliya V. Klovach, and Kirill K. Kivva \\ Russian Federal Research Institute of Fisheries and Oceanography, Russian Federation, 17 V.Krasnoselskaya, \\ Moscow, Russia
}

Keywords: Far East salmon stocks, long-term climate change, 60-year cycle, record salmon catch of 2018, sea surface temperature anomalies, chlorophyll "a"

\section{Introduction}

The analysis of catch statistics of Far East salmons for more than 100-year period (1911-2018) has revealed some features of their long-term variations, characterized by the 55-70 year-cycle (Klyashtorin and Lyubushin 2007). It was also found that periods of high abundance and biomass of salmon stocks coincided with the warming in the Northern Hemisphere in 1916-1945 and 1982-2013. However, the climatic reasons of warming in the North Pacific for these two periods were different (Krovnin et al. 2016, 2018). The growth of the Far East salmon stocks in 1916-1945 was associated with warming of surface water in the eastern ocean which extended westward along the Aleutian Islands to the coast of Kamchatka and the eastern Sea of Okhotsk. The second period of high biomass and, respectively, catches of the Far East salmons coincided with a sharp warming of surface water in the western and central North Pacific.

Despite the relationship between high stock levels of Far East salmons and North Pacific warming, its biophysical mechanisms are still not clear. It is generally assumed that an increase in mean annual sea surface temperature is favorable for development and survival of juvenile salmon during the early marine period of their life cycle and increases survival of fish during the first wintering in the ocean. However, there is no reliable confirmation of these assumptions. Therefore, more attention to environmental conditions in the spawning rivers during the warming periods is required.

Multidecadal variability of climate and its use for predicting the tendencies of salmon abundance

The 60-year periodicity is observed in the long-term variations of many climatic indices both in the North Atlantic (Atlantic Multidecadal Oscillation (AMO), North Atlantic Oscillation (NAO), Atmospheric Circulation Index (ACI), proposed by Klyashtorin and Lyubushin (2007)) and North Pacific (Pacific Decadal Oscillation (PDO), Aleutian Low Pressure Index (ALPI)) that suggests the existence of a single climatic signal, at least within the hemisphere. Klyashtorin and Lyubushin (2007) showed that the long-term changes in salmon abundance better corresponded to dynamics of the ACI calculated for the North Atlantic sector than to dynamics of the North Pacific indices (PDO and ALPI).

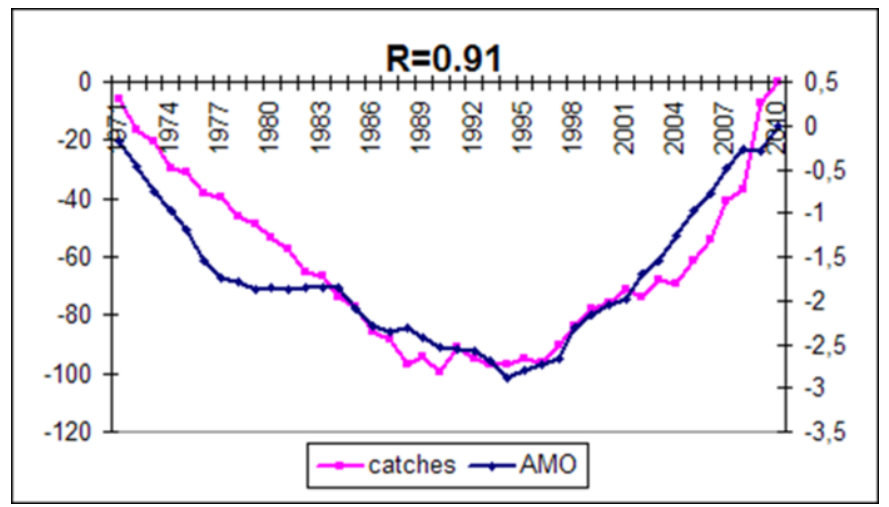

Fig. 1. Cumulative sums of anomalies of total Far East salmon catches and AMO index.

In 1971-2010, there was a high positive relationship between cumulative sums of anomalies of the AMO index and catches of Far East salmons (Fig. 1). This is confirmed also by Table 1, in which loadings of the first two principal components of the 34 climatic and Far East salmon catch time series for the 1972-2010 period is given. In this Table, rows "Regions $1 \mathrm{~A} \div 6 \mathrm{~A}$ and $1 \mathrm{P} \div 5 \mathrm{P}$ " designate area-averaged sea surface temperature anomalies (SSTA) in the North Atlantic and North Pacific regions identified on the basis of the cluster analysis (Fig. 2), and rows "PC1" and "PC2" correspond to time series of the first two principal components of the joint SSTA field in the 
northern oceans. All climatic characteristics are calculated for the winter season (January-March). As seen from the Table 1, PC1 (27.6\%) of 34 physical and biological time series is determined by AMO $(r=0.91)$ and is characterized by high positive correlations with the main Far East salmon stocks. Moreover, this PC shows the high positive correlation coefficients with SSTA in the southwestern North Pacific and North Pacific index (NPI). PC2 $(17.3 \%)$ is clearly associated with the PDO $(r=-0.78)$, but its correlations with catches of Far East salmons are not statistically significant.

\begin{tabular}{|l|c|c|}
\hline \multirow{2}{*}{\multicolumn{1}{|c|}{ VARIABLE }} & PC1 & PC2 \\
\cline { 2 - 3 } & $27,60 \%$ & $17,30 \%$ \\
\hline North Atlantic Oscillation (XII-III) & $-0,04$ & 0,53 \\
\hline Arctic Oscillation (XII-III) & 0,00 & 0,72 \\
\hline West Atlantic TP & 0,19 & $-0,65$ \\
\hline East Atlantic TP & 0,19 & $-0,05$ \\
\hline Scandinavia pattern & $-0,33$ & $-0,38$ \\
\hline TropicaliNH pattern & $-0,27$ & 0,53 \\
\hline Pacific/North American TP (XII-III) & 0,43 & $-0,46$ \\
\hline North Pacific Index & 0,55 & 0,58 \\
\hline West Pacific TP & 0,32 & $-0,05$ \\
\hline Southern Oscillation Index (XII-III) & $-0,14$ & 0,51 \\
\hline Atlantic Multidecadal Oscillation & 0,91 & $-0,26$ \\
\hline Tw at Kola Section (0-200 m) & 0,42 & 0,44 \\
\hline Tropical North Atlantic & 0,66 & $-0,56$ \\
\hline Region 1A & 0,56 & 0,45 \\
\hline Region 2A & 0,54 & 0,40 \\
\hline Region 3A & 0,75 & $-0,18$ \\
\hline Region 4A & 0,59 & $-0,46$ \\
\hline Region 5A & 0,94 & $-0,04$ \\
\hline Region6A & $-0,12$ & 0,31 \\
\hline Region 1P & 0,24 & $-0,53$ \\
\hline Region 2P & 0,13 & 0,70 \\
\hline Region 3P & $-0,22$ & $-0,16$ \\
\hline Region 4P & 0,78 & 0,25 \\
\hline Region 5P & 0,74 & 0,45 \\
\hline PC1 (28.9\%) & 0,84 & $-0,28$ \\
\hline PC2 (17.6\%) & 0,34 & 0,62 \\
\hline Pacific Decadal Oscillation & 0,18 & $-0,78$ \\
\hline North Pacific Gyre Oscillation & 0,29 & 0,22 \\
\hline WK pink (even years) & 0,86 & $-0,01$ \\
\hline EK pink (odd years_ & 0,67 & 0,22 \\
\hline South Kurils pink & 0,60 & 0,12 \\
\hline WK sockeye & 0,85 & 0,10 \\
\hline EK sockeye & 0,57 & $-0,06$ \\
\hline EK chum & 0,46 & \\
\hline & & \\
\hline
\end{tabular}

Table 1. Loadings of the first 2 principal components of the 34 climatic and salmon catch time series for the 1972 2010 period.

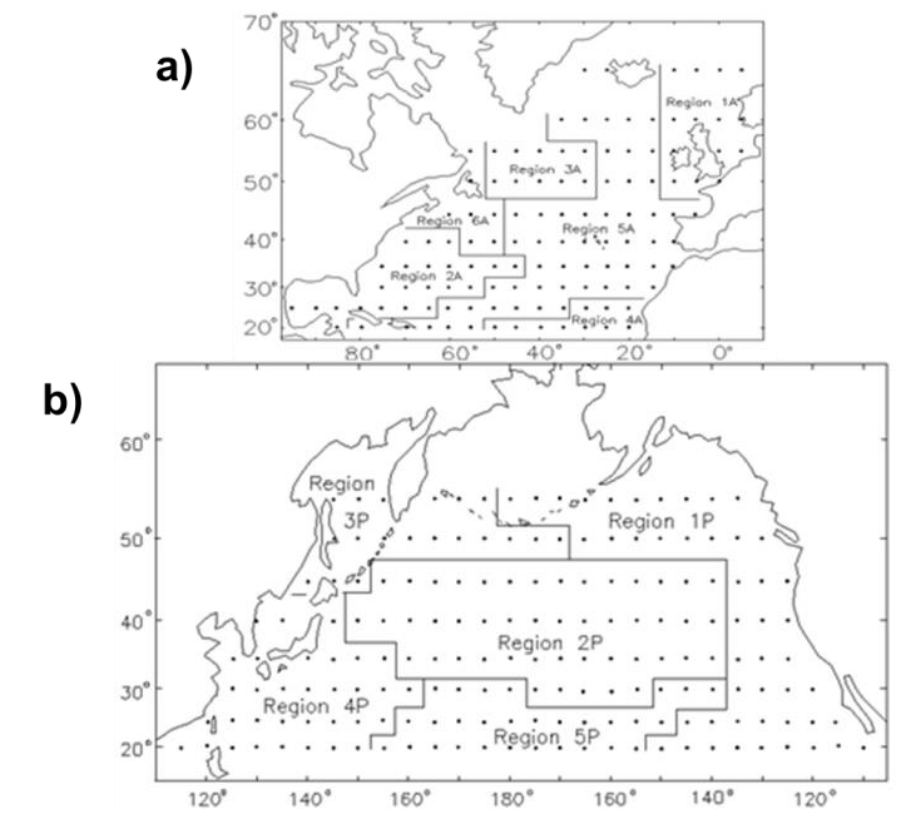

Fig. 2. Results of cluster analysis of mean winter SSTA field in the North Atlantic (a) and North Pacific (b) (Krovnin 1995). 
Thus, the increase in salmon catches in 1990s-2000s were associated, to a great extent, with climatic processes in the North Atlantic sector. The effects of the North Atlantic climate variability on the winter North Pacific SST were realized via the teleconnection patterns over the Eurasian sector. There was evidence of strengthening of the North Atlantic impact on the western North Pacific since the late 1970s, associated with the eastward shift of the NAO centers. The shift to warmer SST regime in the western North Pacific in the late 1980s corresponded well to shifts in the state of the Eurasian teleconnection patterns. However, we do not know exactly which biophysical mechanism(s) lies behind the growth of Far East salmon stocks during this period of warming. Favorable conditions that promote the development and survival of juvenile salmon as they migrated from rivers into the sea have been forming since the late 1970s.At the same time, an increase in SST in the western and central North Pacific has been associated with cooling in traditional wintering areas in the Gulf of Alaska and off the eastern Aleutian Islands, which may result in wintering fish moving westward into warmer waters. .

The existence of the 60-year cycle in variations of the Far East salmon stocks and climatic characteristics became a basis for predicting the trends of salmon abundance several decades in advance (Klyashtorin and Lyubushin 2007). These authors predicted decrease in catches from the early 2000s till the early 2020s. However, it is clear now that their forecast was not realized (Fig. 3), for a few reasons. Firstly, the ACI calculated for the North Atlantic region does not completely reflect the whole complexity of processes in the climatic system of the ocean. In particular, it does not consider longitudinal and latitudinal shifts of the large-scale atmospheric centers in the region (Icelandic Low and Azores High) which result in differences in mechanisms of the North Atlantic impact on the western North Pacific climate. Secondly, the 60-year signal was obtained on a basis of relatively short time series which length did not exceed 150 years. This period covers only about two and a half cycles. Thus, the cycle has low reliability compared to the PDO index. The period of its variations during the last two decades was reduced from 50-60 to 10-15 years due to intensifying the short-term variability in the North Pacific climate. During the last 10 years there were very considerable variations in catch volumes of main Far East pink salmon stocks. These wide variations in pink salmon catches, and in a broader context, in their stocks were associated with the abovementioned changes in climatic conditions.

Nevertheless, the use of multi-decadal variability in climatic parameters is now perhaps the only way to predict tendencies in Far East salmon stocks for 20-30 years in advance.

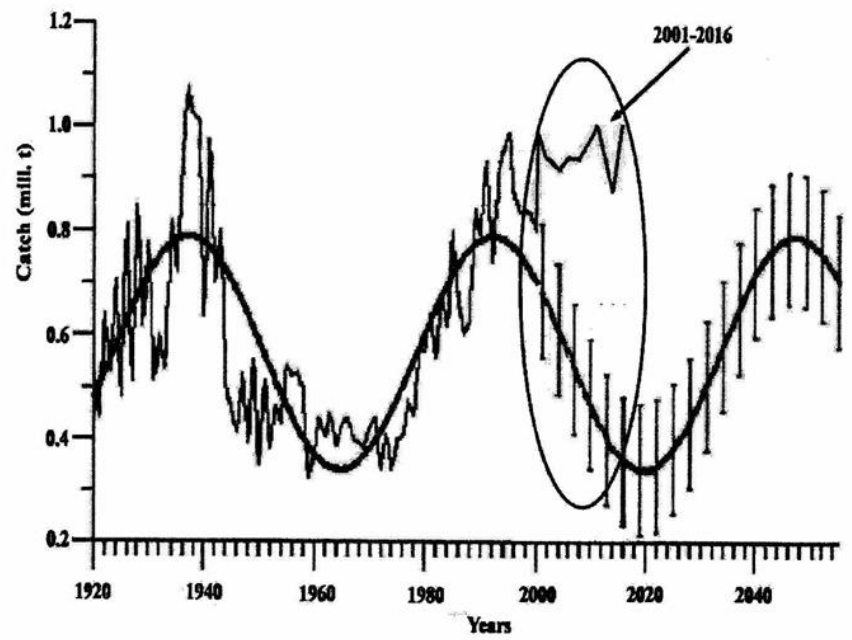

Fig. 3. Long-range forecast of total Pacific salmon catches based on cyclic character of changes in their stock (Klyastorin and Lyubushin 2007). Ellipse covers the period of discrepancy between actual and predicted catches.

Environmental conditions in the North Pacific during 2017-2018

The period from 2014 to 2018 was characterized by drastic surface warming in the northern North Pacific including the Bering and eastern Okhotsk Seas. This warming started in the Northeast Pacific in January 2014, and then spread westward to the Kamchatka coasts. Finally, this led to essential increases in catches of East and West Kamchatka salmon stocks, such as pink salmon. In some sense, the situation of the last five years repeats the situation of the 1916-1945 period.

Despite the similarity of climatic conditions during 2014-2018, which were favorable for the formation of very strong year classes of salmon stocks, in 2018 the unprecedented record catch of Far East salmons exceeded 677,000 metric tons, was fixed. This drastic growth of total catch was, to a great extent, associated with a four-time 
increase in West Kamchatka pink salmon catch, compared with previous even 2016 year (301,316 metric tons and 74,823 metric tons, respectively), while the East Kamchatka pink salmon catch increased from 68,990 metric tons in 2016 to 111,250 metric tons in 2018 , i.e., 1.6 times.
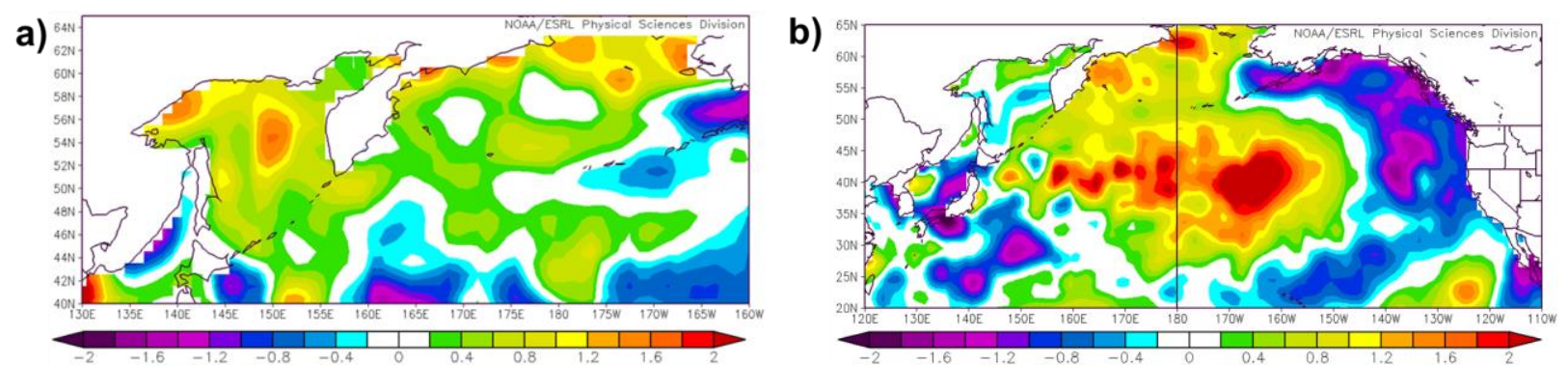

Fig. 4. Differences of SSTA in May-June between 2017 and 2015 (a) and SSTA in January-April between 2018 and 2016 (b).

It is interesting to compare thermal conditions for Kamchatka pink salmon stocks at different stages of their marine period of life cycle for generations of 2014 and 2016 years.

Figure 4a shows the difference of the North Pacific SSTA in May-June between 2015 and 2017, i.e., during the early marine period of life of the 2014 and 2016 generations. Apparently, in the coastal waters of West Kamchatka SST in 2017 was higher, on the average, by $0.7-0.9^{\circ} \mathrm{C}$ than in 2015 ; off the northeastern coast of the peninsula this difference exceeded $1.0^{\circ} \mathrm{C}$. In our opinion, such thermal differences hardly became the reason of sharp improvement of growth and survival of the 2016 generation, in comparison with the 2014 generation. Wintering conditions for two consecutive even generations of the Kamchatka pink salmon in 2016 and 2018 were somewhat different. In particular, the 2018 SST off the Pacific side of the eastern and central Aleutian Islands decreased essentially (by $1.2-1.6^{\circ} \mathrm{C}$ ) though it remained above the norm (Fig. $4 \mathrm{~b}$ ). At the same time, SST in the central part of the ocean increased considerably. The area of positive differences of SSTA (up to $1.0-1.2^{\circ} \mathrm{C}$ ) stretched to the north up to the Chukotka coast. The observed changes in temperatures may result in the shift of wintering pink salmon concentrations to the west and to the southwest from the traditional areas, but how this could affect the 2018 catch remains unclear. It is quite probable that warming of the considerable water area to the west of $165-170^{\circ} \mathrm{W}$ could favor expansion of total wintering area and cause high survival of the 2016 Kamchatka pink salmon generations in the winter of 2017-2018. The summer season of 2018 was colder than in 2016. Along the migration routes for spawning, SST was close to norm, and off the both Kamchatka coasts SSTA reached $0.8-1.2^{\circ} \mathrm{C}$ (Fig. 5). Once again, it remains unclear how this could affect the approaches of pink salmon to the peninsula.
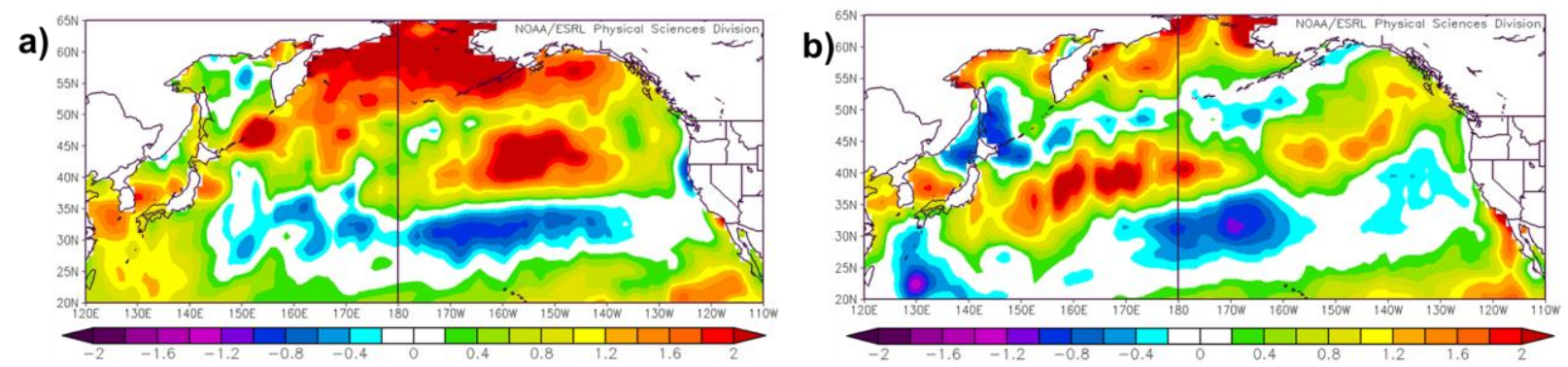

Fig. 5. SSTA patterns in the North Pacific in July-August: 2016 (a), 2018 (b)

One more reason for the record catch in 2018 may be the production of very favorable food conditions. We used the data on chlorophyll "a" concentration as an indicator of food abundance. Analyses and visualizations used in this study were produced with the Giovanni online data system, developed and maintained by the NASA GES DISC (https://giovanni.gsfc.nasa.gov/giovanni/). Chlorophyll "a" characterizes intensity of photosynthesis, and, thus, it can be considered as an indicator of phytoplankton biomass, the primary chain of food web, which eventually determines conditions of salmon feeding.

We considered the annual changes in chlorophyll "a" concentrations for Kamchatka pink salmon generations in 2011, 2014, and 2016 for four regions of the North Pacific (Fig. 6). In waters off of West Kamchatka, the spring peaks of chlorophyll "a" content in 2015 and 2017 (during the earliest marine period of West Kamchatka 2014 and 2016 pink salmon generations) almost coincided in time and continued from beginning of April to mid-June (Fig. 
7a). Moreover, the maximum concentrations in 2015 were more than 1.5 times higher than in 2017 . Thus, it is not likely that food conditions for West Kamchatka pink salmon juveniles in 2017 were much better than in 2015.

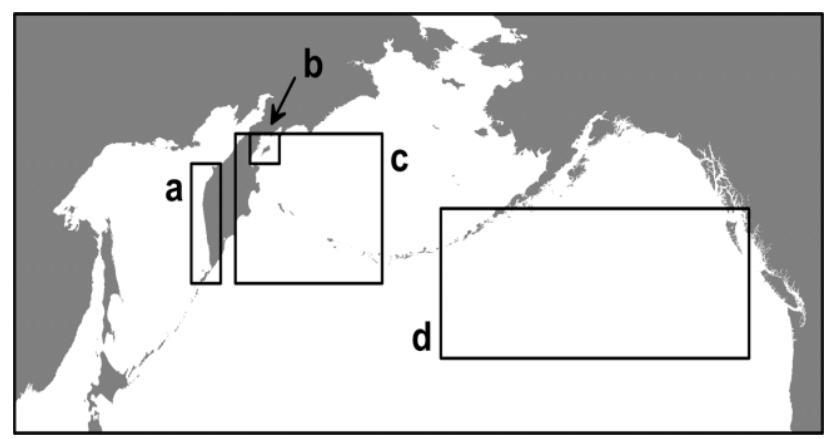

Fig. 6. North Pacific regions, for which chlorophyll "a" concentrations were calculated and averaged.

In the Karaginsky Gulf, where East Kamchatka juvenile pink salmon migrate from rivers, the peak of chlorophyll "a" concentration in 2017 was observed in mid-May, while in 2015 it was noted one month earlier, though the secondary maximum was fixed in the first decade of May (Fig. 7b). The maximal zooplankton development is commonly observed one month later than that of phytoplankton. Thus, it is very possible that maximal zooplankton development in mid-June could match the mass migration of juvenile pink salmon into the sea that created very good feeding conditions for very good feeding conditions for fish during their migration. Note the strong peak of chlorophyll "a" in early May of 2012, but possibly it occurred too early to form favorable feeding conditions for the 2011 generation, which was poor.
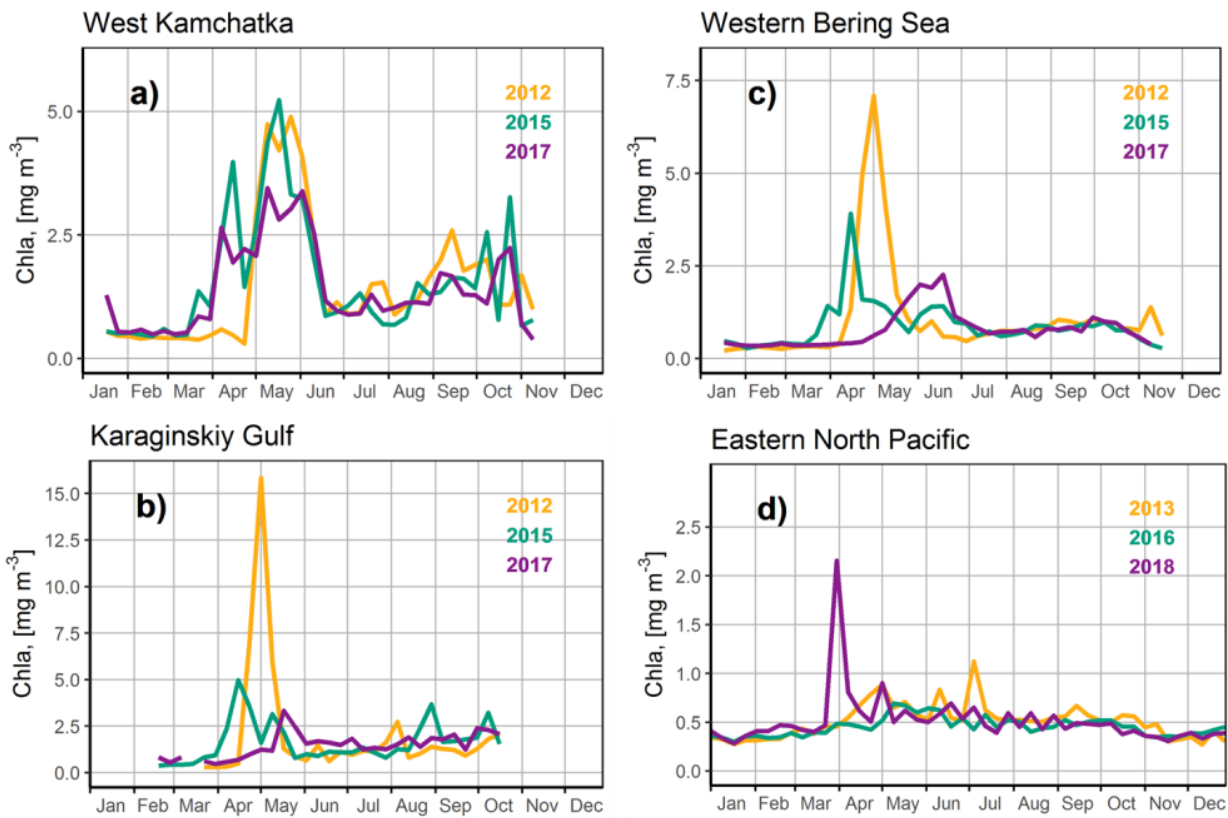

Fig. 7. Annual changes in chlorophyll "a" concentration.

An interesting situation was observed in the southwestern Bering Sea, where young East Kamchatka pink salmon migrate in summer for feeding. The peak of chlorophyll "a" concentration in 2017 was fixed there in midJune, two months later than in 2015 (Fig. 7c). This possibly favored the formation of very good conditions for pink salmon feeding in the second half of summer and early autumn of 2017 and could contribute to the higher biomass and, as a result, higher catches of this stock in 2018, compared to 2016.

Finally, in the Northeast Pacific main wintering area of Kamchatka pink salmon stocks, there was a very prominent maximum of chlorophyll "a" in late March of 2018, which was not observed in either 2013 or 2016 (Fig. $7 \mathrm{~d})$. It is very likely that this resulted in a formation of favorable feeding conditions and better survival of pink salmon in the 2018 winter-spring period before their spawning migrations toward the Kamchatka. 
Overall, these results did not allow us to identify one specific factor responsible for the record catch of Far East salmons in 2018. Most likely, they were the result of a combination of subtle changes in environmental and feeding conditions throughout 2017-2018.

\section{Conclusion}

Long periods of changing abundance and biomass of Pacific salmons are clearly associated with the corresponding climatic "epochs" and may be predicted with some degree of certainty. However, the reasons for very sharp increase/decrease in catch during the specific long period of high/low abundance are uncertain and require special consideration and research.

\section{REFERENCES}

Klyashtorin, L.B. and A.A. Lyubushin. 2007. Cyclic climate changes and fish productivity. Moscow. VNIRO Publishing. 224 pp.

Krovnin, A.S. 1995. A comparative study of climatic changes in the North Pacific and the North Atlantic and their relation to abundance of fish stocks. In R.J. Beamish (Editor). Climate change and northern fish populations. Can. Spec. Publ. Fish Aquat. Sci. No. 121: 181-198.

Krovnin, A.S., B.N. Kotenev, and N.V. Klovach. 2016. Association of "salmon epochs" in the Far Eastern region with large-scale climate changes in the North Pacific. Trudy VNIRO 164: 22-40. (in Russian).

Krovnin, A.S., B.N. Kotenev, and N.V. Klovach. 2018. Present state and future of Far East salmon stocks under changing climate. N. Pac. Anadr. Fish Comm. Tech. Rep. 11: 51-55. (Available at https://npafc.org) 